\title{
Tools of the trade - and how to use them
}

\author{
The role of physicists in finance is changing, as quantitative trading opens an exciting alternative to \\ traditional financial modelling, and data science lures would-be 'quants' away. But the void is being \\ steadily filled by a new type of analyst.
}

When Fischer Black and Myron Scholes hit upon a mathematical expression for eliminating trading risk in the 1960s, they couldn't have foreseen the impact it would have on the world at large. They certainly wouldn't have anticipated the familiar sight, some 30 years later, of a trading floor flooded with physicists. But the Black-Scholes equation is to financial derivatives pricing what the advectiondiffusion equation is to particles, so physicists were obvious moths to the flame. And indeed, the mass migration of physicists towards quantitative finance has been connected to the misuse of models that led to the global financial crisis (GFC) of 2007-2008. But now another shift is upon us, and its implications are yet to surface.

Options contracts were being sold in London as early as the 1690s, but their history may even go back as far as ancient Greece. Today's standard option grants its holder the right to buy (or sell) a financial asset at a specific price on a given date. For example, the option to sell pounds sterling at an inflated rate this time last year would have been a good bet to place before the pound took the post-Brexit dive that no one was expecting.

But the beauty of the Black-Scholes equation is that you don't need to bet: the profits are guaranteed by a pricing strategy that hedges all risk. Of course, as many have noted, neither life nor financial markets are as Gaussian as the equation would have us believe, so when extreme events hit, they have the potential to hit hard. There still is some debate over what exactly precipitated the GFC, but much has been made of oversimplifying assumptions attributed to quantitative analysts - or 'quants' - many of whom held physics PhDs. And although these assumptions may not have been made were it not for the physicists, one might argue that they are best placed to ensure it doesn't happen again.

Because, additional regulation measures aside, the modelling mindset that has run finance for the last 40 years is still being used. The only shift seems to be a relative slowing of the movement of physics $\mathrm{PhDs}$ into finance. The reasons for this are likely twofold. First, the burgeoning world of data science has attracted many recent doctoral graduates, a trend that may explain the American Institute of Physics' estimation that fewer than half of graduates in 2013 and 2014 took up postdoctoral positions ${ }^{1}$, down from almost two thirds of the classes in 2009 and 2010 (ref. 2). And second, the quantitative finance world is quickly filling up with so-called financial engineers, armed with custom-designed graduate qualifications.

\section{"Everyone should understand the difference between a model and reality and no one should be astonished at the inability of one- or two-inch equations to represent the convolutions of people and markets."}

The proliferation of graduate programmes in financial engineering across the globe might be seen as one of the side effects of the quantitative renaissance in finance. The Carnegie Mellon master's degree in computational finance, widely regarded as the first financial engineering programme of its kind, was only established in 1994. Now, the QuantNet Community website lists over 30 comparable programmes in North America alone, many of which were established in the last decade ${ }^{2}$. These courses typically last between 12 and 18 months and aim to equip students with a sound knowledge of the financial models developed since the days of Black and Scholes.

And therein, perhaps, lies a problem. As Emanuel Derman notes in his book ${ }^{3}$, "Everyone should understand the difference between a model and reality and no one should be astonished at the inability of one- or two-inch equations to represent the convolutions of people and markets." Derman, a former particle physicist, was one of the first to make the move to finance in 1985. Were you to enrol in his master's degree in financial engineering at Columbia University, you would no doubt have this drilled into you. But is the same degree of scepticism touted in other programmes?

One of the benefits of having physics PhDs on the trading floor - indeed, one of the reasons they were co-opted into the industry at all - is their inherent bent towards a healthy level of scepticism. As Andrew Lo and Mark Mueller noted ${ }^{4}$ in their post-crisis appeal to the industry, physicists "rely on the ongoing dialogue between theoretical ideals and experimental evidence" even as they covet mathematical elegance. "This rational, incremental, and sometimes painstaking debate between idealized quantitative models and harsh empirical realities has led to many breakthroughs in physics, and provides a clear guide for the role and limitations of quantitative methods in financial markets, and the future of finance."

By contrast, the stated goal of most financial engineering programs is to teach students existing models and how to apply them - not to question where or when they might fail. That's not to say that the best and brightest graduates won't be capable of doing so, but the programmes are seemingly not designed with that in mind.

The silver lining for physics $\mathrm{PhDs}$ is that even as quant roles are being filled with financial engineers, a new role is taking shape. Physicists are now being recruited - largely by hedge funds - as quantitative traders or researchers, whose job it is to devise new models for making money. And while there are still traditional modelling roles being filled by physicists, perhaps being on the inside is the only way to clean up the mess that Black and Scholes inadvertently created.

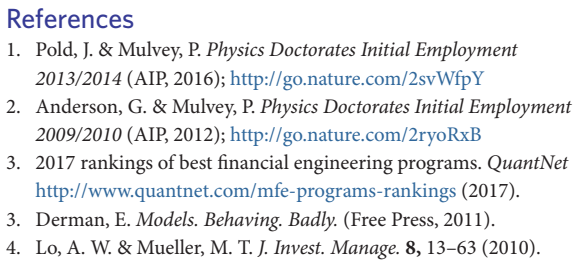

